\title{
Feasibility of three-dimensional (3D) balanced steady-state-free-precession (bSSFP) myocardial perfusion MRI at 3 Tesla using local RF Shimming with dual-source RF transmission
}

Roy Jogiya ${ }^{1 *}$, Andreas Schuster $^{1}$, Arshad Zaman², Yasmine Samaroo ${ }^{1}$, Eike Nagel ${ }^{1}$, Sebastian Kozerke ${ }^{3,1}$, Sven Plein ${ }^{2,1}$

From 16th Annual SCMR Scientific Sessions

San Francisco, CA, USA. 31 January - 3 February 2013

\section{Background}

Three-dimensional myocardial perfusion MRI offers better myocardial coverage than conventionally used two-dimensional methods. bSSFP three-dimensional myocardial perfusion MRI at 3 Tesla potentially offers further improvement of signal characteristics and may enhance the use of three-dimensional myocardial perfusion MRI for clinical application.

\section{Methods}

Twenty-five healthy volunteers and 2 patients were included upon written informed consent and local ethics committee approval. Dynamic contrast-enhanced 3D bSSFP perfusion imaging was performed on a 3 Tesla MRI scanner equipped with dual-source RF transmission technology (MultiTransmit; Philips Healthcare, The Netherlands).

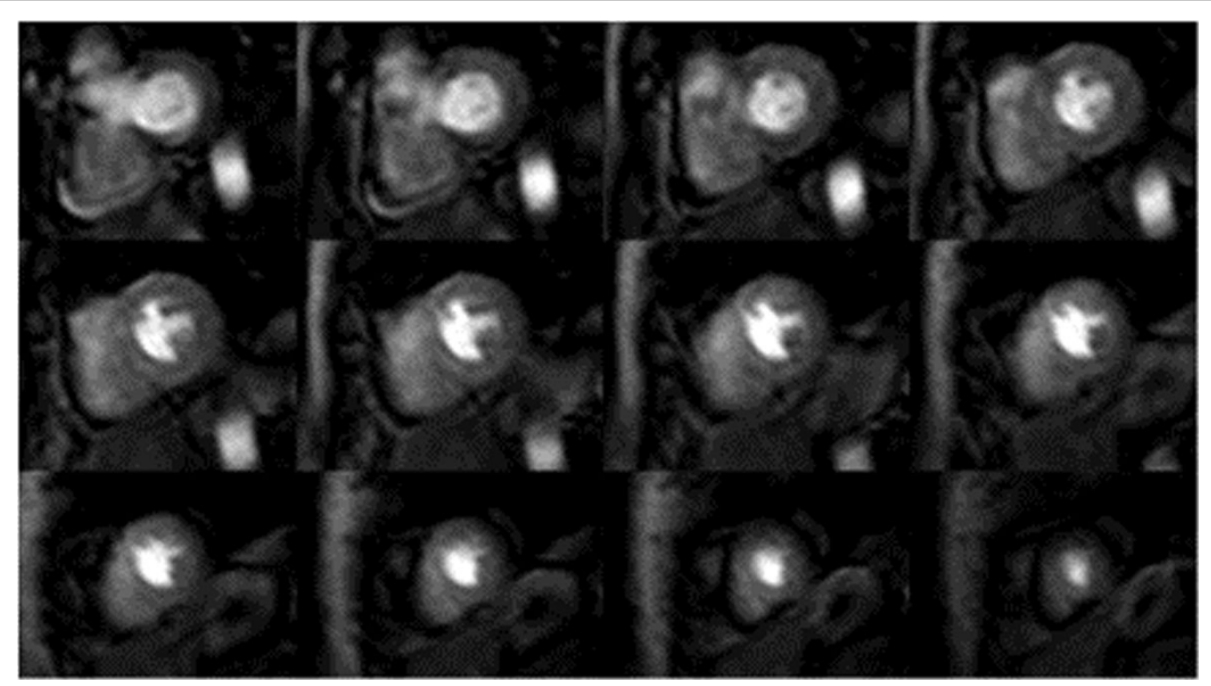

Figure 1 Volunteer example of 3D balanced steady state free precession (bSSFP) acquisition

${ }^{1}$ Kings College London, London, UK

Full list of author information is available at the end of the article

(c) 2013 Jogiya et al; licensee BioMed Central Ltd. This is an Open Access article distributed under the terms of the Creative Commons 


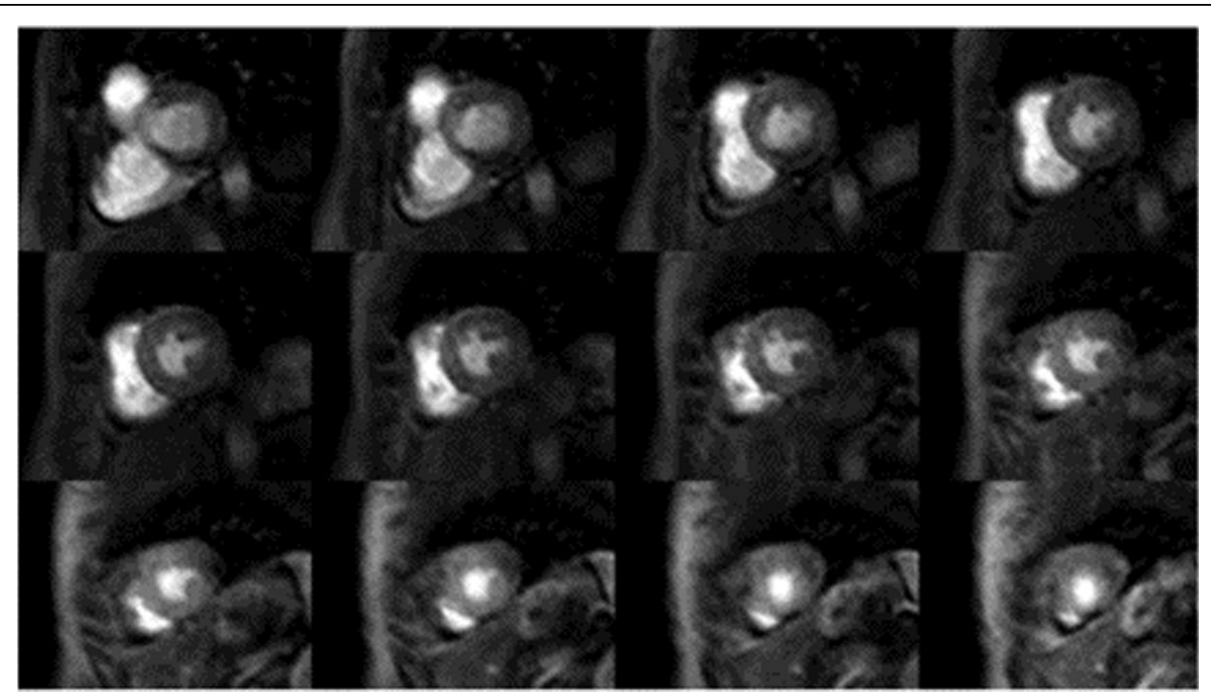

Figure 2 Volunteer example of 3D spoiled gradient echo (TFE) acquisition

\section{Results}

Local RF Shimming with dual source RF transmission significantly improved B1 field homogeneity $(\mathrm{P}=0.0107)$. For bSSFP perfusion imaging, it allowed a reduction of TR from 3.4 to $2.2 \mathrm{~ms}$ at the same flip angle. Image quality was similar for TFE and bSSFP but there were more artefacts for bSSFP (Figure 1).

Compared with an equivalent 3D spoiled gradient echo method (TFE), mean SNR was (30.4 vs 24.4, respectively, $\mathrm{P}=0.24$ ), but signal homogeneity measured in the myocardium was improved (14.98\% vs $11.15 \%$, respectively, $\mathrm{p}=0.015$ ).

\section{Conclusions}

Three-dimensional bSSFP myocardial perfusion MRI using local RF Shimming with dual-source RF transmission at 3 Tesla is feasible with improved signal characteristics. Image artifacts however remain an important limitation.

\section{Funding}

Prof. Plein is funded by British Heart Foundation fellowship FS/10/62/28409 and receives research grant support from Philips Healthcare.

Prof. Kozerke receives funding from the Swiss National Science Foundation (grant number CR3213_132671/1) and research support form Bayer (Switzerland) AG. Prof. Nagel receives grant support from Bayer Healthcare and Philips Healthcare.

\section{Author details}

${ }^{1}$ Kings College London, London, UK. ${ }^{2}$ Leeds University, Leeds, UK. ${ }^{3} \mathrm{ETH}$ Biomedical Engineering, Zurich, Switzerland.
Published: 30 January 2013

doi:10.1186/1532-429X-15-S1-P23

Cite this article as: Jogiya et al:: Feasibility of three-dimensional (3D) balanced steady-state-free-precession (bSSFP) myocardial perfusion MRI at 3 Tesla using local RF Shimming with dual-source RF transmission. Journal of Cardiovascular Magnetic Resonance 2013 15(Suppl 1):P23.

Submit your next manuscript to BioMed Central and take full advantage of:

- Convenient online submission

- Thorough peer review

- No space constraints or color figure charges

- Immediate publication on acceptance

- Inclusion in PubMed, CAS, Scopus and Google Scholar

- Research which is freely available for redistribution 